Jurnal

Kardiologi Indonesia

J Kardiol Indones. 2015;36:202-8

ISSN 0I26/3773

Clinical Research

\title{
Trimetazidine Effect on Neutrophils count in Post IKKP
}

\author{
Taka Mehi, Yoga Yuniadi, Nur Haryono
}

Department of Cardiology and Vascular Medicine, Faculty of Medicine, Universitas Indonesia, and National Cardiovascular Center Harapan Kita, Jakarta
Background: Reperfusion strategy, either with thrombolytic or Primary Percutaneous Coronary Intervention (PPCl), is the core treatment for Acute ST-Segment Elevation Myocardial Infarct (STEMI). The goal of PPCI is to restore the patency of infarcted epicardial artery and establish microvascular reperfusion as soon as possible so that necrotic myocardial area can be reduced. However, successful restoration of infarcted epicardial artery is not always followed by enough reperfusion to the microvascular part. Trimetazidine can reduce neutrophil which was mediated by tissue trauma during ischemic heart condition. Unfortunately, its influence over neutrophil accumulation in acute STEMI patients which undergo $\mathrm{PPCl}$ is not well understood.

Method: There were 68 consecutive-selected acute STEMI patients which undergo PPCl since January 2015 until Juni 20I5. They were admitted in emergency department. Peripheral vein blood sampling was taken to measure neutrophil before PPCl was performed. Six hour after PPCI was conducted, another peripheral vein blood sampling was taken for another neutrophil measurement. Neutrophil measurement was performed with Sysmex 2000i. Statistical analysis was performed by using SPSS 17.

Result: Among 68 patients, divided in two groups, trimetazidine 28 patients and plasebo 40 patients. There were no differences amount of neutrophils in trimetazidine or plasebo group, before or after PPCl. Neutrophil pre $\mathrm{PPCl}$ in trimetazidine vs plasebo group $10.71 \pm 3.263$ vs $10.99 \pm 3.083$, $\mathrm{p}: 0,34 \mathrm{I}$. Neutrophil post PPCl in trimetazidine vs plasebo group $9.49 \pm$ 3.135 vs $9.92 \pm 3.463$, p:0,664.

Conclusion: There were no reducing amount of neutrophils after trimetazidine was given in patients STEMI which underwent PPCI.

(J Kardiol Indones. 20I5;36:202-8)

Keywords: Acute STEMI; Neutrophil;No reflow;PPCI;Reperfusion Injury; Trimetazidine 


\title{
Pengaruh Trimetazidine Terhadap Jumlah Netrofil Pasca IKPP
}

\author{
Taka Mehi, Yoga Yuniadi, Nur Haryono
}

\begin{abstract}
Latar belakang : Reperfusi miokardium adalah terapi utama pada pasien IMA EST. Namun keberhasilan mengembalikan patensi dari arteri koroner epikardial setelah oklusi tidak menjamin cukupnya reperfusi ke level mikrovaskular, yang disebut sebagai fenomena no reflow. Salah satu penyebab no reflow adalah jejas reperfusi yang menyebabkan infiltrasi masif dan aktivasi netrofil yang akan mengeluarkan radikal bebas oksigen, enzim proteolitik dan mediator proinflamasi yang secara langsung menyebabkan kerusakan jaringan dan endotel. Trimetazidine menurunkan netrofil setelah jantung mengalami jejas reperfusi. Akan tetapi belum diketahui pengaruh trimetazidine terhadap akumulasi netrofil pada IMA EST yang dilakukan IKPP. Metode : Sebanyak 68 pasien IMA EST yang menjalani IKPP dipilih secara konsekutif sejak Januari 2015 - Juni 2015, dilakukan pengambilan darah vena perifer untuk menghitung jumlah netrofil sebelum IKPP. Dibagi menjadi dua kelompok, plasebo dan trimetazidine. Kemudian pasien menjalani IKPP. Setelah 6 jam paska IKPP dilakukan pengambilan kembali darah vena perifer untuk menghitung netrofil paska IKPP. Hitung netrofil diperiksa dengan Sysmex 2000i. Statistik dinilai dengan SPSS 17.

Hasil : Dari 68 subyek, dibagi menjadi 28 subyek pada kelompok yang diberikan trimetazidine dan 40 subyek yang diberikan plasebo. Tidak didapatkan perbedaan jumlah netrofil pada kelompok perlakuan dan kontrol baik sebelum maupun sesudah IKPP, netrofil pre IKPP pada trimetazidine vs plasebo $10.71 \pm 3.263$ vs $10.99 \pm 3.083$, p:0,341. Netrofil post IKPP pada trimetazidine vs plasebo $9.49 \pm 3.135$ vs $9.92 \pm 3.463$, p:0,664.

Kesimpulan : Tidak terdapat penurunan jumlah netrofil pasca pemberian trimetazidine pada pasien IMA EST yang menjalani IKPP.
\end{abstract}

(J Kardiol Indones. 2015;36:202-8)

Kata kunci: Akut STEMI ; Neutrofil ; ada reflow ; PPCI ; Reperfusi Cedera ; trimetazidine

A ngka perawatan di rumah sakit karena infark miokardium akut dengan elevasi segmen ST (IMA EST) masih tinggi dan bervariasi pada berbagai negara. Salah satu contoh registri IMA EST yang paling komprehensif berasal

\footnotetext{
Alamat Korespondensi

Taka Mehi, Department of Cardiology and Vascular Medicine, Faculty of Medicine, Universitas Indonesia, and National Cardiovascular Center Harapan Kita, Jakarta. E-mail: taka_mehi@yahoo.com
}

dari Swedia, dengan jumlah sekitar 66/100.000/ tahun. ${ }^{1}$ Sebagai perbandingan di Jakarta Barat angka kejadian IMA EST di Jakarta Barat saja yang berasal dari beberapa rumah sakit mencapai 566 pasien dalam jangka waktu 5 bulan. $^{2}$ Sekarang ini, reperfusi miokardium dengan trombolitik atau intervensi koroner perkutan primer ( IKPP) adalah terapi utama pada pasien yang mengalami IMA EST. Tujuan utama IKPP untuk mengembalikan patensi arteri epikardial yang mengalami infark dan mencapai reperfusi mikrovaskular secepat mungkin, sehingga dapat 
mengurangi perluasan trauma ireversibel atau nekrosis miokardium. ${ }^{3}$ Namun keberhasilan mengembalikan patensi dari arteri koroner epikardial setelah oklusi tidak selalu menjamin cukupnya reperfusi ke level mikrovaskular. Data dari McMannus case fatality rate pada pasien IMA EST saat di rumah sakit mencapai angka 9,7 \%.4 Fenomena obstruksi mikrovaskular (MVO) itu disebut dengan no reflow. ${ }^{5}$ Terdapat dua mekanisme yang berperan pada MVO yaitu disfungsi mikrovaskular dan kerusakan integritas mikrostruktur endotel. Kerusakan endotel dapat disebabkan oleh berbagai hal, antara lain terpapar kembali oleh oksigen dengan jumlah yang banyak pada beberapa menit pertama reperfusi akan mencetuskan terjadinya radikal bebas dan peroksinitrit, endotel mengalami disfungsi dan akan menurunkan jumlah oksida nitrit. ${ }^{6}$ Pada saat terjadi jejas reperfusi, terjadi infiltrasi netrofil dan platelet secara masif kedalam mikrosikulasi. ${ }^{7}$ Terjadi aktivasi netrofil yang akan mengeluarkan radikal bebas oksigen, enzim proteolitik dan mediator proinflamasi yang secara langsung menyebabkan kerusakan jaringan dan endotel. ${ }^{8} \mathrm{Hal}$ ini memperlihatkan peran penting netrofil dalam mekanisme no reflow.

Studi eksperimental yang dilakukan oleh Tritto dkk menyatakan trimetazidine dapat menurunkan akumulasi netrofil yang dimediasi oleh trauma jaringan setelah jantung mengalami iskemia. Kemampuan trimetazidine menurunkan jumlah netrofil merupakan mekanisme yang penting menjelaskan peranan trimetazidine pada jantung yang mengalami iskemia. ${ }^{9}$ Akibatnya luas infark menurun dan risiko kerusakan miokard yang menjadi lebih kecil.

Saat ini trimetazidine sudah disetujui dan dikenal sebagai obat anti-angina yang bersifat metabolik. Sejauh ini belum diketahui secara luas pengaruh pemberian trimetazidine terhadap akumulasi netrofil pada kejadian IMA EST yang dilakukan tindakan IKPP.

Akumulasi netrofil berperan pada kejadian MVO. Trimetazidine dapat mengurangi akumulasi netrofil pada binatang percobaan, tetapi belum diketahui peranan trimetazidine terhadap akumulasi netrofil pada pasien IMA EST yang dilakukan IKPP. Penelitian ini dilakukan untuk mengetahui peranan trimetazidine dalam menurunkan jumlah netrofil pada pasien IMA EST yang menjalani IKPP.

\section{Mekanisme netrofil mediated injury}

Netrofil berperan pada mekanisme dasar iskemia pada jejas reperfusi, kecenderungan trauma terhadap miokardium dan komponen sel (terutama endotel pembuluh darah koroner, mikrovaskular dan miosit) sebagai respon primer miokardium terhadap mediator proinflamasi, yang mengubah arah respon normal inflamasi yaitu dengan menetralisasi proses invasi jaringan miokardium. Proses yang berperan dalam terjadinya trauma jaringan oleh netrofil yaitu melalui pembentukan oksigen radikal bebas, degranulasi dan pengeluaran protease, dan mediator proinflamasi lain nya. Netrofil adalah komponen inflamasi yang dominan dalam jejas setelah iskemia. Pada jejas reperfusi terjadi infiltrasi masif netrofil dan platelet ke mikrosirkulasi koroner, terpapar kembali netrofil pada miokardium setelah iskemia akan merangsang terjadinya aktivasi netrofil. Netrofil akan adesi ke permukaan endotel dan migrasi ke jaringan sekitarnya. Aktivasi netrofil ini akan mengeluarkan Reactive Organ Species (ROS), enzim proteolitik dan mediator proinflamasi yang secara langsung akan menyebabkan kerusakan jaringan miokardium dan endotel. ${ }^{3}$ Netrofil mengeluarkan lebih dari 20 enzim proteolitik yang berbeda seperti acid hydrolase, serine protease elastase yang terletak didalam granula azurophilic, dan metalloproteinases collagenase dan gelatinase. Elastase berperan mengkatalisis pemecahan berbagai macam substrat seperti kolagen tipe III dan IV, imunoglobulin, komplemen, fibronectin, dan proteoglikan. Target utama enzim proteolitik adalah matriks ekstraseluler dan elastin, kolagen, dan proteoglikan. Netrofil juga sebagai sumber primer dari ROS, termasuk anion superoksida, yang akan dipecah menjadi hidrogen peroksida (H2O2) oleh superoksida dismutase. Terapi antinetrofil berperan penting dalam proteksi miokardium terhadap jejas reperfusi. ${ }^{10}$

\section{Mekanisme kerja trimetazidine}

Trimetazidine (1-[2,3,4-trimethoxybenzyl] piperazine) adalah obat antiangina yang tidak memiliki efek hemodinamik, tidak mempengaruhi kebutuhan maupun supply oksigen miosit seperti obat antiangina lainnya. Obat ini juga diduga memiliki efek sitoprotektif pada miokardium yang mengalami iskemia dengan cara mempengaruhi langsung miosit. Mencegah penurunan produksi ATP, ${ }^{11}$ menurunkan asidosis intraseluler dan menjaga homeostasis intraseluler yang dapat berubah dengan adanya pencetus seperti kalsium dan sodium overload ${ }^{12}$ dan paparan oksigen radikal bebas. ${ }^{13}$ 


\section{Peranan trimetazidine dalam menurunkan akumulasi netrofil}

Trimetazidine berperan dalam mengurangi kejadian jejas reperfusi dengan cara mempengaruhi akumulasi netrofil, dapat dinilai dari penelitian yang dilakukan Wiliam dkk, didapatkan akumulasi netrofil yang bermakna pada area at risk kelompok kontrol, sedangkan pada kelompok trimetazidine jumlah nya sangat menurun. $\underline{14}$

\section{Subyek dan Metode}

Penelitian ini adalah suatu penelitian eksperimental, dilakukan di Pusat Jantung Nasional Harapan Kita Jakarta. Dilakukan dari Januari 2015 sampai Juni 2015. Sampel penelitian diambil dari pasien IMA EST yang masuk ke UGD RS PJNHK kemudian menjalani IKPP. Pasien yang telah mendapat terapi trimetazidine sebelumnya tidak disertakan sebagai subyek penelitian. Sampel dibagi menjadi dua kelompok. Kelompok 1 adalah kelompok yang akan mendapat dosis tunggal trimetazidine $70 \mathrm{mg}$ sebelum IKPP, dan kelompok 2 adalah kelompok yang mendapat plasebo. Sebelum mendapat perlakuan akan di ambil darah vena perifer untuk dilakukan hitung jumlah netrofil. Kemudian pasien menjalani IKPP. Enam jam setelah IKPP dilakukan pengambilan kembali darah vena perifer untuk dilakukan penghitungan netrofil. Penghitungan jumlah netrofil dilakukan dengan menggunakan mesin otomatis Sysmex-XT2000i.

Pengolahan data penelitian dilakukan secara elektronik menggunakan perangkat SPSS 17. Karakteristik dasar dan klinis subjek penelitian disajikan dalam bentuk tabel. Data numerik disajikan dalam rerata \pm standar deviasi dan median jika sebaran data tidak normal. Uji t test berpasangan dilakukan untuk mengetahui delta jumlah netrofil sebelum dan sesudah IKPP. Batas kemaknaan ialah $\mathrm{p} \leq 0.05$ dengan 95\% interval kepercayaan.

\section{Hasil}

Selama periode penelitian, terkumpul 68 subyek yang terdiri dari 28 subyek pada kelompok trimetazidine dan 40 subyek kelompok plasebo. Karakteristik pasien dapat dilihat pada Tabel 1. Terdapat perbedaan

Tabel 1. Karakteristik dasar

\begin{tabular}{|c|c|c|c|}
\hline & $\begin{array}{l}\text { Plasebo } \\
\mathrm{N}=40\end{array}$ & $\begin{array}{l}\text { Trimetazidine } \\
\mathrm{N}=28\end{array}$ & $\mathrm{P}$ \\
\hline Laki-laki (\%) & $36(90)$ & $21(75)$ & $<0,01$ \\
\hline Usia (tahun) & $55,1 \pm 10,45$ & $57,57 \pm 10,23$ & 0,71 \\
\hline Diabetes (\%) & $9(22,5)$ & $5(17,9)$ & $<0,01$ \\
\hline Hipertensi (\%) & $25(62,1)$ & $19(67,9)$ & 0,01 \\
\hline Merokok (\%) & $26(65)$ & $17(60,7)$ & 0,03 \\
\hline Riwayat keluarga (\%) & $7(17,5)$ & $5(17,9)$ & $<0,01$ \\
\hline Dislipidemia (\%) & $17(42,5)$ & $9(32,1)$ & 0,05 \\
\hline Diagnosis IMA EST & & & 0,46 \\
\hline - Anterior & $15(37,5)$ & $16(57)$ & \\
\hline - Non anterior & $25(62,5)$ & $12(42,9)$ & \\
\hline Awitan (jam) & $6,16 \pm 2,8$ & $6,08 \pm 2,2$ & 0,90 \\
\hline Door to balloon time (menit) & $100 \pm 31,27$ & $101 \pm 61,9$ & 0,43 \\
\hline Culprit lesion (\%) & & & $<0,01$ \\
\hline - LAD & $16(40)$ & $18(64,3)$ & \\
\hline$-\mathrm{LCx}$ & $4(10)$ & $2(7,1)$ & \\
\hline - RCA & $20(50)$ & $8(28,6)$ & \\
\hline
\end{tabular}

LAD : Left anterior descending artery : LCx : Left circumflex artery : RCA : right coronary artery, IMA-EST : infark miokardium akut dengan elevasi segmen ST. 
proporsi dari data jenis kelamin, faktor risiko, dan culprit lesion, sedangkan untuk diagnosis, awitan dan door to balloon time tidak terdapat perbedaan proporsi data.

Analisis bivariat dilakukan untuk mencari faktor faktor yang berhubungan dengan jumlah netrofil sesudah IKPP. Dari Tabel 2 dapat dilihat jumlah netrofil sesudah IKPP tidak dipengaruhi oleh usia, jenis kelamin, merokok, Diabetes mellitus, riwayat keluarga, culprit lesion dan dislipidemia. Jumlah netrofil sesudah IKPP nampaknya menurun dipengaruhi oleh diagnosis non anterior dan door to balloon time yang lama.

Tabel 2. Demografi faktor - faktor risiko, diagnosis, door to ballon time, culprit lesion dan jumlah netrofil sesudah IKPP ( $\mathrm{n}=68$ )

\begin{tabular}{|c|c|c|c|}
\hline & $\begin{array}{c}\text { Crude regression } \\
\text { coefficient }\end{array}$ & $\begin{array}{l}95 \% \text { interval } \\
\text { kepercayaan }\end{array}$ & $\mathrm{p}$ \\
\hline Usia & -0.317 & $-0.108-0.044$ & 0.409 \\
\hline Konstanta & 11.416 & & \\
\hline Jenis kelamin & -0.971 & $-3.098-1.156$ & 0.365 \\
\hline Konstanta & 10.76 & & \\
\hline Merokok & -0.201 & $-1.836-1.432$ & 0.806 \\
\hline Konstanta & 9.76 & & \\
\hline $\mathrm{DM}$ & -0.346 & $-2.294-1.601$ & 0.724 \\
\hline Konstanta & 9.703 & & \\
\hline Riw Keluarga & -0.464 & $-2.529-1.600$ & 0.655 \\
\hline Konstanta & 9.714 & & \\
\hline Culprit lesion & -0.361 & $-1.185-0.463$ & 0.385 \\
\hline Konstanta & 10.322 & & \\
\hline Dislipidemia & 0.47 & $-1.147-2.088$ & 0.563 \\
\hline Konstanta & 9.452 & & \\
\hline Diagnosis & -3.612 & $-2.707-0.407$ & 0.145 \\
\hline Konstanta & 11.408 & & \\
\hline DBT & -0.016 & $-0.033-0.000$ & 0.051 \\
\hline Konstanta & 11.377 & & \\
\hline Hipertensi & 2.007 & $0.433-3.581$ & 0.013 \\
\hline Konstanta & 8.333 & & \\
\hline Awitan & 0.431 & $0.148-0.714$ & 0.003 \\
\hline Konstanta & 7.003 & & \\
\hline
\end{tabular}

DM : Diabetes mellitus, DBT : Door to balloon time
Sedangkan sebaliknya adanya hipertensi dan awitan yang lama akan meningkatkan jumlah netrofil sesudah IKPP.

Kemudian dilakukan analisis multivariat faktor - faktor yang akan mempengaruhi jumlah netrofil sesudah IKPP. Didapatkan tiga faktor yang berkaitan dengan jumlah netrofil sesudah IKPP. Subyek penelitian yang memiliki faktor risiko hipertensi dan awitan yang lama akan menaikkan jumlah netrofil. Sebaliknya dengan penambahan usia dan pasien dengan diagnosis non anterior IMA EST akan mengalami penurunan jumlah netrofil. Dapat dilihat pada Tabel 3.

Pada Tabel 4 terlihat penurunan signifikan jumlah netrofil sebelum dan sesudah IKPP pada masingmasing kelompok trimetazidine dan plasebo.

Kemudian dilakukan uji statistik untuk menilai bagaimana perbedaan netrofil pada masing - masing kelompok trimetazidine dan plasebo, tidak didapatkan perbedaan jumlah netrofil pada kelompok perlakuan dan kelompok kontrol baik sebelum maupun sesudah IKPP. Dapat dilihat pada Tabel 5.

Tabel 3. Faktor - faktor dominan yang mempengaruhi jumlah netrofil sesudah IKPP

\begin{tabular}{lccc}
\hline & $\begin{array}{c}\text { Koefisien } \\
\text { regresi }\end{array}$ & $\begin{array}{c}95 \% \text { Rentang keper- } \\
\text { cayaan }\end{array}$ & $\mathrm{p}$ \\
\hline Hipertensi & 2.71 & $1.09-4.34$ & 0.001 \\
Usia & -0.79 & $-0.15--0.004$ & 0.038 \\
Diagnosis & -1.39 & $-2.85-0.06$ & 0.061 \\
Awitan & 0.43 & $0.167-0.687$ & 0.002 \\
Konstanta & 11.407 & $9.781-19.250$ & 0.000 \\
\hline
\end{tabular}

IKPP : Intervensi koroner perkutan prime

\section{Diskusi}

Pada penelitian ini tidak didapatkan perbedaan jumlah netrofil pada kelompok perlakuan dan kelompok kontrol baik sebelum maupun sesudah IKPP, walaupun terjadi penurunan jumlah netrofil pada masing - masing kelompok yang bermakna secara statistik. Temuan ini tidak sesuai dengan hipotesis

Tabel 4. Perbedaan jumlah netrofil sebelum dan sesudah IKPP

\begin{tabular}{lccc}
\hline & Netrofil sebelum IKPP & Netrofil sesudah IKPP & P \\
\hline Trimetazidine & $10.71 \pm 3.263$ & $9.49 \pm 3.135$ & 0,001 \\
Plasebo & $10.99 \pm 3.083$ & $9.92 \pm 3.463$ & 0,017 \\
\hline
\end{tabular}

IKPP : Intervensi koroner perkutan primer 
peneliti karena kemungkinan adanya patogenesis jejas reperfusi. Piper dan Dorado menyatakan, jika efek pemberian trimetazidine terhadap jejas reperfusi pada pasien yang dilakukan intervensi tertentu, ternyata tidak sesuai dengan hipotesis, ada kemungkinan terjadi prevensi oleh intervensi yang kita lakukan, atau kemungkinan lain efek dari iskemia reperfusi yang terjadi sangat besar sehingga menimbulkan kematian sel karena nekrosis atau apoptosis. $\underline{15}$

Pada analisis bivariat didapatkan beberapa faktor yang mungkin dapat mempengaruhi jumlah netrofil sesudah IKPP, kemudian dilanjutkan dengan analisis multivariat yang pada akhirnya mendapatkan 4 faktor yang berpengaruh terhadap jumlah netrofil sesudah IKPP yaitu, tekanan darah yang lebih tinggi dan awitan yang semakin lama akan meningkatkan jumlah netrofil sesudah IKPP, sedangkan penambahan usia dan diagnosis non anterior akan menurunkan jumlah netrofil sesudah IKPP, namun penjelasan ilmiah mengenai hubungan faktor - faktor tersebut dengan jumlah netrofil sesudah IKPP belum didapatkan.

Studi yang dilakukan Khaled dkk, menilai kemampuan trimetazidine sebagai obat anti iskemia yang bermanfaat dalam menurunkan jejas reperfusi pada pasien IMA EST yang dilakukan IKPP, melalui penilaian myocardial salvage index menggunakan SPECT tidak berhasil menunjukkan perbedaan outcome pada masing - masing kelompok perlakuan dan plasebo. Pada penelitian ini pasien mendapat trimetazidine sebelum dilakukan IKPP, didapatkan hasil myocardial salvage index yang relatif sama pada masing - masing kelompok trimetazidine vs plasebo $29.71 \pm 24.4 \%$ vs $21.43 \pm 21.5 \%$ dengan nilai $p$ yang tidak bermakna, penelitian ini memiliki kekurangan yaitu dilakukan hanya pada satu tempat dan jumlah sampel yang sedikit. ${ }^{16}$

Penelitian yang dilakukan Kim dkk, meneliti tentang bagaimana perbedaan klinis pasien yang diberikan trimetazidine selama perawatan dirumah sakit dibandingkan dengan pasien yang tidak mendapat trimetazidine. Kemudian diteliti hasil luaran klinis berupa major adverse cardiac events (MACE), didapatkan risiko relatif MACE lebih rendah pada kelompok yang mendapat trimetazidine dibandingkan yang tidak mendapat terapi (angka kejadian 2.3 vs $.9 .5 \%$; hazard ratio $0.24,95 \% \mathrm{CI}$ $0.10-0.56, \mathrm{P}=0.001) .{ }^{17} \mathrm{Pada}$ penelitian kami hanya memberikan single dose sebelum IKPP, bila merujuk pada penelitian Kim dkk ada tempatnya kita memberikan trimetazidine tidak hanya single dose namun diteruskan saat masa rawatan.

Pengambilan sampel darah pada penelitian ini dilakukan sebelum tindakan IKPP, kemudian 6 jam pasca IKPP, pertimbangan pengambilan darah pada masa ini berdasarkan studi sebelumnya trimetazidine mulai bekerja pada onset 2 jam dan mencapai puncak dalam 5 - 8 jam pasca pemberian. ${ }^{18}$

Dari penelitian ini, rerata waktu pengambilan darah pasca IKPP 7,3 \pm 1,7 jam. Oleh Chatelain, yang melakukan penilaian jumlah netrofil di vena perifer pada hewan coba yang dilakukan oklusi pada arteri anterior desenden kiri selama 3 jam, lamanya netrofil bersirkulasi dalam darah vena selama 8,4 \pm 0,7 jam. ${ }^{19}$ Studi eksperimental yang dilakukan Zhao dkk juga menemukan bahwa netrofil yang teraktivasi terakumulasi di dalam pembuluh darah dalam 6 jam pertama pasca jejas reperfusi kemudian akan mengalami migrasi dalam 24 jam ke miokardium. ${ }^{20}$

Penelitian ini memiliki beberapa keterbatasan. (1). Jumlah netrofil diambil dari darah vena perifer, bukan diambil intra koroner dari arteri terkait infark, yang mungkin saja dapat berbeda hasilnya, tetapi studi dari Bonvini menyatakan bahwa pada pasien pasca reperfusi akan terjadi peningkatan respon inflamasi sistemik dan regional. ${ }^{21}$ Studi dari Ranjadalayan menyatakan pada pasien IMA pasca revaskularisasi akan terjadi peningkatan jumlah netrofil di sirkulasi perifer yang akan diikuti oleh terjadi nya aktivasi yang mungkin dikarenakan reperfusi miokardium, ${ }^{22}$ sehingga penilaian jumlah netrofil dengan akses perifer masih dapat dilakukan pada subyek penelitian kami. (2). Penelitian ini hanya menilai penurunan jumlah netrofil pada jejas reperfusi bukan kejadian no reflow yang merupakan end point yang lebih bernilai klinis. Penilaian fenomena no reflow menggunakan myocardial blush grade kami sarankan dilakukan pada penelitian berikutnya.

\section{Kesimpulan}

Tidak didapatkan penurunan jumlah netrofil pasca pemberian trimetazidine pada pasien IMA EST yang menjalani IKPP.

\section{Daftar Pustaka}

1. Steg G, James SK, Atar D, Badano LP and Borger MA. ESC Guidelines for the management of acute myocardial infarction 


\section{Jurnal Kardiologi Indonesia}

in patients presenting with ST-segment elevation. European Heart Journal. 2012; 33: 2569-619.

2. Soerianata S and Juzar DA. iSTEMI Network Pilot Program West Jakarta. Jakarta2014.

3. Niccoli G, Burzotta F, Galiuto L and Crea F. Myocardial NoReflow in Humans. Journal American College of Cardiology. 2009; 54: $281-92$

4. David D. McManus, Gore J, Yarzebski J, Spencer F, Lessard D and Goldberg RJ. Recent Trends in the Incidence, Treatment, and Outcomes of Patients with ST and Non-ST-Segment Acute Myocardial Infarction. Am J Med. 2011; 124: 40-7.

5. Ito H, Tomooka T, Sakai N, Yu H, Higashino Y and Fujii K. Lack of Myocardial Perfusion Immediately After Successful Thrombolysis A Predictor of Poor Recovery of Left Ventricular Function in Anterior Myocardial Infarction. Circulation 1992; 85: 1699-705.

6. Kang $S$ and Yang Y. Coronary microvascular reperfusion injury and no-reflow in acute myocardial infarction. Clin Invest Med 2007; 30(3): E133-E45.

7. Reffelmann $\mathrm{T}$ and Kloner RA. The "no-reflow" phenomenon: basic science and clinical correlates. Heart Journal. 2002; 87: 162-8.

8. Engler RL, Schmid-Schonbein GW and Pavelec RS. Leukocyte Capillary Plugging in Myocardial Ischemia and Reperfusion in the Dog. American Journal Pathology. 1983; 111: 98-111.

9. Tritto I, Wang P, Kuppusamy P, Giraldez R, Zweier JL and Ambrosio G. The anti-anginal drug trimetazidine reduces neutrophil-mediated cardiac reperfusion injury. J Cardiovasc Pharmacol. 2005; 46: 89-98.

10. Vinten-Johansen J. Involvement of neutrophils in the pathogenesis of lethal myocardial reperfusion injury. Cardiovascular Research. 2004; 61: 481-97.

11. Lavanchy N, Martin J and Rossi A. [Trimetazidine preservation of the energy potential of the myocardium during ischemia and reperfusion. Phosphorus NMR spectroscopy study of the isolated heart]. Presse Med. 1986; 15: 1758-61.

12. Renaud JF. Internal $\mathrm{pH}, \mathrm{Na}+$, and $\mathrm{Ca} 2+$ regulation by trimetazidine during cardiac cell acidosis. Cardiovascular Drug Therapy. 1988; 6: 677-86.

13. Guarnieri $\mathrm{C}$ and Muscari C. Beneficial effects of trimetazidine on mitochondrial function and superoxide production in the cardiac muscle of monocrotaline-treated rats. Biochemical pharmacology. 1988; 37: 4685-8.

14. F. M Williams KT, M. Kus, T. J Williams. Trimetazidine inhibits Neutrophil Accumulation After Myocadial Ischaemia and Reperfusion in Rabbits. Journal of Cardiovascular Pharmacology. 1993; 22: 828-33.

15. H.M.Piper, D.Garcia-Dorado and M.Ovize. A fresh look at reperfusion injury. Cardiovascular Research. 1998; 38: 291-300.

16. Foad Khaled EA, Bastawy Islam,Khaled Saeed. E ect of trimetazidine on myocardial salvage index in patients with acute ST segment elevation myocardial infarction undergoing primary PCI. The Egyptian Heart Journal. 2013; 65: 181-9.

17. Kim J, Kim C, Chun K, et al. Effects of trimetazidine in patients with acute myocardial infarction: data from the Korean Acute Myocardial Infarction Registry. Clinical Research in Cardiology. 2013; 102: 915-22.

18. Weerawadee Chandranipapongse SC, Tullaya Ruangnapa, Suthathip Ngokpol, Korbtham Sathirakul, Piyapat Pongnarin. Bioequivalence Study of Two Formulations of $35 \mathrm{mg}$ Trimetazidine Modified Release Tablets in Healthy Thai Volunteers Under Fasting and Fed Conditions. J Bioequiv 2011; 3: 052-5.

19. Chatelain P, Latour JG, Tran D, de Lorgeril M, Dupras G and Bourassa M. Neutrophil accumulation in experimental myocardial infarcts: relation with extent of injury and effect of reperfusion. Circulation. 1987; 75: 1083-90.

20. Zhi Qing Zhao MN, Ning Ping Wang, Karlene O, Robert A Guyton,et al. Dynamic Progression of Contractile and Endothelial Dysfunction and Infarct Extension in the Late Phase of Reperfusion. Journal Of Surgical Research. 2000; 9: 133-44.

21. Robert F Bonvini TH, Edoardo Camenzind. Inflammatory response post-myocardial infarction and reperfusion : a new therapeutic target? European Heart Journal Supplements. 2005; 7: $127-36$.

22. Kulasegaram Ranjadayalan VU, Simon W Davies, Denise Syndercombe-Court, Charles N Gutteridge, Adam D Timmis. Thrombolytic treatment in acute myocardial infarction: neutrophil activation, peripheral leucocyte responses, and myocardial injury. Br Heart J 1991; 66: 10-4. 